\title{
NOTAS EDITORIALES
}

\section{Adriano Díez Jiménez \\ Director/editor CRSC}

\author{
Roxana Fontalvo Gómez \\ Asistente de editor CRSC
}

Collectivus, Revista de Ciencias Sociales (CRCS), en esta presente publicación del volumen 7, número 1, ofrece en la primera sección, siete (7) artículos monográficos dedicados al "Homenaje a la tradición del pensamiento crítico. Reflexiones sobre la obra de Orlando Fals Borda". Como antecedente a la publicación de este monográfico, en el año 2018 el Programa de Sociología de la Universidad del Atlántico, bajo la dirección y coordinación del profesor Blas Zubiría, organizó la primera Cátedra Orlando Fals Borda, a raíz de los diez (10) años de su muerte, abriendo un espacio de reflexión en torno a su obra y temáticas presentes desde lo local, regional, nacional y latinoamericano.

A tenor de lo anterior, se planteó reconocer en un monográfico de la revista, el pensamiento y obra de la sociología colombiana, a partir del legado del maestro Orlando Fals Borda. Para ello, se llevó a cabo una convocatoria titulada "Homenaje a la tradición del pensamiento crítico. Reflexiones sobre la obra de Orlando Fals Borda", convocatoria que coordinó el profesor Blas Zubiría Mutis, conocedor en profundidad del pensamiento falsbordiano.

En la segunda sección titulada "otros artículos", se presentan tres (3) artículos atinentes a la temática general de la revista, cuyo aporte contribuye significativamente, a la realidad y diversidad investigativa latinoamericana.

El primero de estos artículos cuenta con la autoría de Nuria Arellanes y Laura Iñigo, titulado Las redes sociales y el consumismo: Del futuro colectivo al algoritmo de Facebook, trabajo que reflexiona sobre las transformaciones tecno-sociales en el mundo, poniendo de relieve el uso de la red de Facebook y las repercusiones que tiene esta plataforma dentro de la lógica consumista sobre sus usuarios.

Wilman Preciado y Heidi Pulido en su artículo El papel de las mujeres sobrevivientes en la construcción de paz en Colombia, analizan las contribuciones realizadas por las mujeres sobrevivientes del conflicto armado a la paz en Colombia, teniendo en cuenta el punto de vista de éstas sobre la violencia patriarcal y sus aportes a la construcción de la paz.

El artículo destaca, además, el empoderamiento femenino a raíz de la violencia armada, a partir de estrategias pacíficas que buscan contribuir a una movilización social solidaria capaz de reconocer sus vivencias y contribuir al fortalecimiento de la paz colombiana.

El último el artículo de esta sección, es de Cynthia Ferrari El entramado de actores entre política social y economía social en Argentina: Una mirada relacional local, trabajo que propone examinar la orientación territorial y principios de la economía social y solidaria de las políticas sociales, durante el segundo mandato argentino de Cristina Fernández de Kirchner. Para ello, la autora se basó en técnicas de recolección de información como entrevistas, observación y análisis de documentos oficiales que contribuyen a la caracterización de la dimensión relacional de la política social analizando el entramado de actores locales que conforman el Prist - At y las relaciones entre ellos. 


\title{
HOMENAJE A LA TRADICIÓN DEL PENSAMIENTO CRÍTICO. REFLEXIONES SOBRE LA OBRA DE ORLANDO FALS BORDA
}

\author{
Blas Zubiria Mutis \\ Universidad del Atlántico, Barranquilla, Colombia \\ Editor invitado
}

\begin{abstract}
"Quiero hacer esta proclamación de partida porque así me he sentido para tomar mis más importantes decisiones en los trabajos que he realizado: como del Sur del mundo, latinoamericano, colombiano y costeño; y últimamente también como declarado tropical. (...) He tendido más bien a referenciar lo universal en las especificidades de mis gentes y culturas, evitando convertirme en parroquial. No fue siempre así, en especial al comienzo de mi periplo profesional. Porque cuando empecé a sentir las incongruencias de la llamada "ciencia universal" aprendida en el Norte al aplicarla a nuestro contexto regional, hube de investigar y entender las raices ambientales e históricas y las razones culturales del pueblo del común que pudieran aclarar aquellas incongruencias, con el fin de ofrecer bases firmes para un cambio social que se ha considerado indispensable".
\end{abstract}

Por Fals Borda (2004). 1925-2008

Desde el 12 de agosto de 2008, fecha del fallecimiento del maestro Orlando Fals Borda, el programa de Sociología de la Universidad del Atlántico, se propuso como tarea un homenaje permanente a quien ha sido, sin lugar a dudas, uno de los sociólogos más representativos e importante del país (Cataño, 2008), y uno de los referentes permanentes de la sociología crítica latinoamericana (Zubiría Mutis, 2008) con una influencia que trasciende hacia los ámbitos de la sociología mundial (Alburquerque, 2013).

La parábola vital del maestro Fals está articulada al proceso de institucionalización de la sociología en América Latina, no sólo por haber sido junto con el cura Camilo Torres Restrepo, el creador del primer programa de sociología en el país, sino porque en su obra se puede seguir el trazado de lo que se llamó "sociología científica" hasta lo que luego se conoció como "sociología crítica", o como lo dice el profesor Vanegas "de la sociología institucionalizada en la de década de 1950 en América Latina bajo la inspiración funcionalista de la sociología predominante en Estados Unidos, a una sociología, que al igual que lo ocurrido tanto en los países del norte como del sur, incorporó la obra de Marx como fuente de interpretación teórica principal" (Vanegas, s.f, p.13). También el profesor Gonzalo Cataño reconoce esta evolución teórica y metodológica del maestro Fals cuando señala dentro de las etapas de su pensamiento que se pasó de una sociología crítica cuyo "rasgo dominante es la afirmación de una ciencia social rigurosa, empírica y teóricamente significativa" (Cataño, 2008, p.80).

Desde la institucionalidad universitaria se generaron diversos procesos encaminados a mantener vivo su legado y a honrar su memoria. El Consejo Superior de la Universidad del Atlántico, mediante la Resolución Nº005 del 14 de agosto de 2008 decretó como reconocimiento "designar a la biblioteca de la Universidad del Atlántico con el nombre de "Orlando Fals Borda" y honrar con su acto la vida y obra de este ilustre barranquillero". A la par, el claustro de profesores del Programa de Sociología presentó ante el Consejo de Facultad, la propuesta de realizar en su honor una Cátedra Caribe de Sociología Orlando Fals Borda, como espacio académico de reflexión no sólo sobre la obra del maestro Fals, sino también sobre las temáticas locales, regionales, nacionales -e incluso latinoamericanas- que estuvieron siempre en el centro de su reflexión sociológica y producción académica.

En el 2018, la Coordinación de la Cátedra Caribe Orlando Fals Borda consideró importante a raíz de los 10 años de la muerte de Fals y articulándose a una propuesta nacional surgida del programa de Sociología de la Universidad Nacional de Colombia, convocar al I Concurso de Ensayo 
Cátedra Caribe Orlando Fals Borda - Diez Años De Retorno A La Tierra. Se abrieron dos modalidades para el concurso: una primera modalidad para sociólogos u otros profesionales de las ciencias sociales que quisieran reflexionar sobre la obra y/o sobre algún problema de la realidad local, regional o latinoamericana desde la perspectiva teórica y metodológica propuesta por el propio Fals. Una segunda modalidad para estudiantes de sociología o de carreras afines que de igual manera presentasen un trabajo relacionado sobre la obra y/o sobre algún problema de la realidad local, regional o latinoamericana desde la perspectiva teórica y metodológica propuesta por el propio Fals. Los ensayos participantes —todos firmados con seudónimo-fueron evaluados en una doble instancia: por un jurado interno encargado de hacer la selección de aquellos que podían ser presentados en la Cátedra y un segundo jurado externo, encargado de seleccionar a los ensayos ganadores en cada una de las dos modalidades.

Apoyándonos en el órgano de difusión del Programa, la Revistas Collectivus, y teniendo como referencia la Cátedra Caribe de Sociología Orlando Fals Borda, 2018, publicamos una convocatoria titulada: Dossier homenaje a la tradición del pensamiento crítico. Reflexiones sobre la obra de Orlando Fals Borda. Convocatoria de la que recibimos numerosos artículos y de los cuales, tras una evaluación de pares externos, de acuerdo a la política editorial de la revista, publicamos en este dossier, aportaciones de los siguientes autores: Normando Suárez; Raimundo Caviedes; Jafte Robles; Daniel Ribero; Felipe Bastidas; Nicolás Herrera; y Lina Marín y Luisa Hoyos.

Esperamos que disfruten de los artículos publicados, pues contribuyen desde sus propias perspectivas a mantener vivo el legado de Orlando Fals Borda.

\section{Referencias bibliográficas}

Alburquerque, G. (2013). El Tercermundismo como Paradigma Científico en América Latina: El pensamiento de Orlando Fals Borda. Universum, 209 - 227.

Cataño, G. (2008). Orlando Fals Borda: sociólogo del compromiso. Revista de Economía Institucional, 79-98.

Fals Borda, O. (2004). Me quieda la angustia de la continuidad. Carta a Pedro Santana Rodríguez. Foro, 108-112.

Vanegas, S. (s.f). Orlando Fals Borda: El legado de hacer ciencia. Bogotá: Universidad Javeriana.

Zubiría Mutis, B. (2008). Rigurosidad académica y compromiso político. Dos constantes en la obra del maestro Orlando Fals Borda. Foro, 46-54. 
